Furness, G. \& Rowley, D. (1956). J. gen. Microbiol. 15, 140-145

\title{
Transduction of Virulence within the Species Salmonella typhimurium
}

\author{
By G. FURNESS AND D. ROWLEY \\ Wright-Fleming Institute of Microbiology, St Mary's Hospital Medical School, \\ Paddington, London, W. 2
}

SUMMARY : Four strains of Salmonella typhimurium avirulent for mice were found to be capable of acting as gene acceptors in transduction experiments. An attempt was made to transduce virulence to three strains, using a typical mouse-virulent strain of S. typhimurium as donor. Two of the strains which are adenine-dependent were successfully made virulent by transduction and simultaneously became adenineindependent. The other strain M 206, whilst possessing the typical antigenic structure of $S$. typhimurium and being non-exacting nutritionally, was not made virulent by transduction.

Although most strains of a bacterial species behave similarly in their virulence for various animals, there are numerous examples of bacterial strains which are atypical in this respect. Bacterial virulence may be dependent on a number of factors and the absence of any one of these may result in loss of virulence. With bacterial strains which are capable of genetic recombination it may be possible to transfer the missing factor from a virulent to an avirulent strain, thus making the latter virulent. This was done in the case of the pneumococcus by Griffith (1928); rough avirulent non-capsulated strains were transformed into smooth virulent capsulated ones, confirming the importance of the capsule for virulence in this species. The present paper deals with attempts to transduce virulence within the species Salmonella typhimurium.

\section{METHODS}

Cultures. Two virulent strains of Salmonella typhimurium were used throughout. Both were smooth strains, and Felix has shown by quantitative agglutination tests (see Felix \& Pitt, 1951) that they are similar both in their ' $O$ ' and heat-labile antigens. One strain, C5, was phage typed by Dr E. S. Anderson and belongs to phage type $2 \mathrm{~A}$ (Felix \& Callow, 1943; Felix, 1956). The other, LT 2, is the propagating strain of S. typhimurium for phage PLT 22 (Zinder \& Lederberg, 1952).

Four avirulent cultures were obtained. The avirulent Salmonella typhimurium M 206 was reported by Dr E. S. Anderson as phage type I (Felix \& Callow, 1943; Felix, 1956). It was smooth and similar to C5 and LT2 quantitatively as regards its ' $\mathrm{O}$ ' and heat-labile antigens. Moreover, it was able to grow on minimal medium (Davis \& Mingioli, 1950). Its avirulence cannot therefore be attributed to its antigenic structure or to a biosynthetic deficiency. It was a mutant from a fully virulent culture from which it differed in virulence and by being sensitive to complement in vitro (Maaløe, 1948). 


\section{Transduction of virulence in $\mathrm{S}$. typhimurium}

The other three cultures, D2, D 10 and 1901 were adenine-dependent strains of S. typhimurium. They were obtained by independent and non-allelic mutations. Both virulent and avirulent strains were able to accept genetic material conveyed by phage PLT 22. All cultures were incubated at $37^{\circ}$.

Bacteriophage. Suspensions of phage PLT 22 (Zinder \& Lederberg, 1952) were used for all transduction experiments. The phage was propagated twice on each new host to ensure that few phage particles carrying the genotype of the original host were present. The optimum concentration of phage particles for transduction was $5 \times 10^{9} / \mathrm{ml}$. Phage suspensions containing over $10^{10}$ particles $/ \mathrm{ml}$. were obtained by propagation in sloppy agar. The clarified lysates were heated at $57^{\circ}$ for $1 \mathrm{hr}$. and tested for sterility. The phage titre was obtained by plaque count by the soft agar layer method (Gratia, 1936), using Salmonella gallinarum SL 140 as indicator strain.

Test animals. Mice (18-22 g.) of a pure line of Swiss white mice no. 1 were used.

Virulence tests. The evaluation of any results depended solely on differences in the virulence of the strains. It was therefore essential to standardize virulence tests in order to obtain reproducible results. Cultures were grown overnight in tryptic digest broth, diluted 1/1000 in warmed tryptic digest broth and $2 \mathrm{ml}$. of this dilution incubated for a further $6 \mathrm{hr}$. Tenfold dilutions of this culture were prepared in saline and $\mathbf{0 . 2} \mathrm{ml}$. of each dilution injected intraperitoneally into each of five mice. The number of viable organisms injected was ascertained from counts prepared in triplicate from the same dilutions, by the drop method of Miles \& Misra (1938). In this medium the number of viable organisms of the avirulent Salmonella typhimurium M 206 averaged $1.5 \times 10^{9} / \mathrm{ml}$. after overnight and $6.5 \times 10^{8} / \mathrm{ml}$. after $6 \mathrm{hr}$. incubation of the diluted culture. Deaths from $S$. typhimurium usually occurred between the 5th and 21 st day and injected mice were observed up to 30 days. After death heart blood was plated out on nutrient agar and on MacConkey's bile salt lactose agar, and incubated overnight. The identity of the culture was confirmed by slide agglutination.

Calculation of LD50. The approximate LD50 was calculated by the method of Reed \& Muench (1938). A single experiment with five mice at each dose level would result in only approximate results, but the virulence of each strain has been confirmed frequently at the critical levels and no large differences have been noted.

Transduction of virulence. Two methods of transduction differing only in detail were used.

To $1 \mathrm{ml}$. of an overnight broth culture of the avirulent strain diluted either $1 / 10$ or $1 / 100$ in warmed broth was added $1 \mathrm{ml}$. of phage suspension (titre $5 \times 10^{9}$ particles $/ \mathrm{ml}$.) which had been harvested from the virulent parents LT 2 or C 5; the mixture was incubated for $4 \mathrm{hr}$.

Alternatively, $3 \mathrm{ml}$. of overnight culture were diluted with $9 \mathrm{ml}$. broth and incubated for $1 \mathrm{hr}$. To $1 \mathrm{ml}$. of this culture $0.1 \mathrm{ml}$. phage suspension (titre $5 \times 10^{10}$ particles $/ \mathrm{ml}$.) was added. After incubation for $30 \mathrm{~min}$. the mixture was diluted tenfold with broth and re-incubated for a further $3 \frac{1}{2} \mathrm{hr}$. 
Prolonged incubation before testing was not essential for detection of transduction unless phenotypic expression of the new character is necessary for survival in the test milieu, as, for instance, in the transfer of drug resistance. It was considered desirable, however, to incubate for $4 \mathrm{hr}$., since besides giving any organisms the opportunity of expressing the new character responsible for virulence, this ensured that the cultures would be in the same phase of growth as in the virulence test.

The mixture was diluted so that $\mathbf{0 . 2} \mathrm{ml}$. contained less than one LD 50 and this amount was injected intraperitoneally into each of ten mice.

A measure of the efficiency of transduction in each experiment was obtained from observation of the transfer of other markers (streptomycin-resistance to strain M206 and prototrophy to strains D2 and D10) in conjunction with a viable count. Where the transfer of streptomycin-resistance was used as a marker, the phage was propagated on a streptomycin-resistant strain of the virulent culture. Two nutrient agar plates containing $500 \mu \mathrm{g}$. streptomycin $/ \mathrm{ml}$. were spread with $0.1 \mathrm{ml}$. amounts of the transduction mixture, incubated overnight, and the number of colonies counted. While lysates from a streptomycin-resistant mutant of the virulent strain were used for both mouse and in vitro tests, some inapparent mutation affecting virulence might have occurred simultaneously with that to streptomycin resistance, and lysates from the streptomycin-sensitive parent were also used for mouse tests. For the transduction of prototrophy the organisms from a sample of the transduction mixture were washed three times in minimal medium and made up to the original volume. Two minimal medium plates (Davis \& Mingioli, 1950) were spread with $0 \cdot 1 \mathrm{ml}$. amounts of the suspension, incubated for $24-36 \mathrm{hr}$., and the colonies were counted.

\section{RESULTS}

It was found that less than 20 organisms of the virulent strains of Salmonella typhimurium C5 and LT2 constituted a lethal dose, the LD50 doses being 14 and 17 organisms, respectively. The avirulent strains of $S$. typhimurium M 206, D2, D10 and 1901 have the same virulence, the LD50 doses being approximately $10^{7}$ organisms. Typical results, for strains $\mathrm{C} 5$ and M 206, are shown in Table 1.

The nature of the medium and small differences in time of incubation were not important, since growth of virulent strains of Salmonella typhimurium in minimal medium, serum broth or digest broth for either 4 or $6 \mathrm{hr}$. gave the same LD50 dose.

Results from different experiments seldom varied, although there were differences in the time elapsing between infection and death. The majority of the mice succumbed to the virulent strains of Salmonella typhimurium between the 5 th and the 21st days. In contrast, those deaths which occurred from the avirulent strains occurred usually within 3 days, and only an occasional animal died later. Even allowing for errors due to the small numbers of mice used at each level, the lethal doses of the virulent and avirulent strains differed by a factor of at least $10^{5}$. 
Table 1. The LD50 doses of Salmonella typhimurium strains C5 and M206

\begin{tabular}{|c|c|c|c|c|c|}
\hline \multirow[b]{2}{*}{ Organism } & \multirow[b]{2}{*}{$\begin{array}{c}\text { No. of } \\
\text { organisms } \\
\text { injected* }\end{array}$} & \multirow[b]{2}{*}{$\begin{array}{c}\text { No. of } \\
\text { mice } \\
\text { injected } \dagger\end{array}$} & \multicolumn{2}{|c|}{ After 30 days } & \multirow[b]{2}{*}{$\begin{array}{c}\text { LD50 dose } \\
\text { (no. of } \\
\text { organisms) }\end{array}$} \\
\hline & & & $\begin{array}{l}\text { Mice } \\
\text { living }\end{array}$ & $\begin{array}{l}\text { Mice } \\
\text { dead }\end{array}$ & \\
\hline S. typhimurium C5 & $\begin{array}{l}1 \cdot 2-2.5 \times 10^{3} \\
1.2-2.5 \times 10^{2} \\
1 \cdot 2-2.5 \times 10^{1} \\
1 \cdot 2-2.5\end{array}$ & $\begin{array}{l}20 \\
25 \\
25 \\
15\end{array}$ & $\begin{array}{r}1 \\
4 \\
6 \\
10\end{array}$ & $\begin{array}{r}19 \\
21 \\
19 \\
5\end{array}$ & 14 \\
\hline S. typhimurium M206 & $\begin{array}{l}1.0-2.5 \times 10^{7} \\
1.0-2.5 \times 10^{6} \\
1.0-2.5 \times 10^{5}\end{array}$ & $\begin{array}{l}16 \\
22 \\
28\end{array}$ & $\begin{array}{r}3 \\
18 \\
26\end{array}$ & $\begin{array}{r}13 \\
4 \\
2\end{array}$ & $9 \times 10^{6}$ \\
\hline
\end{tabular}

* The LD50 dose was estimated on the largest number of organisms injected.

$\dagger$ These numbers represent the sum of separate determinations on different occasions using groups of three or five mice.

\section{Transductions of rirulence}

Three avirulent strains of Salmonella typhimurium (M206, D2, D 10) were examined for the possible transduction of virulence. Transduction of other markers was shown to occur by the transfer of streptomycin resistance to $S$.typhimurium strain M206 and of prototrophy to strains D2 and D10. The maximum proportion of treated cells which were transformed never exceeded $1: 10^{5}$.

Transduction of virulence to those avirulent strains which had an LD50 dose of about $10^{7}$ organisms was attempted, using phage propagated on organisms having an LD 50 dose of less than 20 organisms. To avoid deaths from the avirulent parent after transduction, not more than $10^{6}$ avirulent organisms were injected intraperitoneally into each of ten mice. Thus only if the full virulence of the virulent strain could be transduced to a similar proportion of treated cells as was achieved for other markers-namely 1 in $10^{5}$ organismscould the experiments be expected to succeed. Repeated attempts to obtain virulent recombinants were unsuccessful and as there was no certainty that these conditions would be fulfilled it was necessary to be able to select a few virulent organisms from among many avirulent organisms. Suitable conditions for the enrichment of a few virulent organisms were ascertained from model experiments. Cultures of avirulent strains and a streptomycin-resistant variant of Salmonella typhimurium C5 were grown as for the virulence test. Mixtures were made, such that each mouse on injection received intraperitoneally about 10 virulent and $10^{7}$ avirulent organisms, a ratio of $1: 1,000,000$. Two mice were killed every $24 \mathrm{hr}$. Each was skinned from the tail and the peritoneum washed out with broth in an aseptic manner. The broth was incubated overnight and changes in the ratio of virulent to avirulent organisms were ascertained by making differential counts on streptomycin-containing nutrient agar, to select the original virulent strain, and on nutrient agar to give the total viable count. The ratio gradually narrowed to 1 virulent to 9 avirulent organisms of $S$. typhimurium by the 5 th day.

If the transduction of virulence is possible, this method offers the possibility of selecting a few organisms transformed to virulence. Therefore after trans- 
duction a sample estimated to contain about $10^{6}$ avirulent organisms was injected intraperitoneally into each of ten mice. These were killed between the 4th and 5th day, their peritoneal cavities washed out aseptically with broth and the broth washings incubated overnight. The overnight broth cultures were diluted 1/1000 in broth and incubated $6 \mathrm{hr}$. as for virulence tests. To allow rapid screening of large numbers of cultures, equal volumes of five cultures from the same transduction experiment were pooled, diluted in saline and tested for virulence. If any mice which had received less than one LD50 dose of the avirulent parent died, a post-mortem examination was performed, and a pure culture of the organism recovered and retested for virulence.

Even with this technique it was not possible to select any virulent recombinants of Salmonella typhimurium M206, but from S. typhimurium D2 and D 10 (both auxotrophic for adenine) having LD50 doses of $6 \times 10^{6}$ and $1 \times 10^{7}$ organisms respectively, strains were recovered which were virulent and prototrophic. Moreover, it was found that those strains transduced to prototrophy in vitro and selected on minimal medium agar were also virulent. Prototrophs obtained from D2 and D10 had LD 50 doses of $1 \times 10^{3}$ and $4 \times 10^{2}$ organisms respectively, an increase in virulence of more than 1000 times that of the adenine-dependent parents.

No virulent organisms were recovered from control mice injected with the same numbers of avirulent organisms not treated with lysates of virulent strains. Thus there was no evidence of a spontaneous mutation to prototrophy in vivo. Prototrophic mutants were not obtained with either of these strains when $10^{10}$ organisms were plated on minimal medium agar confirming that in vivo the LD50 dose for mice would be reached before the appearance of prototrophic mutants might be expected.

\section{DISCUSSION}

Where it has been shown that hereditary characters can be transferred from one strain of organism to another, it should be possible to transfer factors responsible for virulence. An increase in mouse virulence can be transduced to Salmonella typhimurium strains D2 or D10, both of which are adeninedependent (auxotrophic) strains, and the recovered organisms, besides being virulent to mice, are prototrophic. Prototrophs obtained by transduction and selection in vitro were also virulent, confirming that in this case the avirulence of the strain was due to a nutritional requirement which was not supplied by the tissue fluids of the mouse. A similar loss of virulence was also found in purine and in $p$-aminobenzoic acid-dependent strains of Salmonella typhi (Bacon, Burrows \& Yates, 1951). Full virulence could be restored to these strains by reversion to prototrophy or by simultaneous injection into mice of the specific growth factor. The transduction of these strains of S. typhimurium to prototrophy and virulence differs, however, from the transformation to toxigenicity in Corynebacterium diphtheriae. In Salmonella typhimurium the transfer of genetic material is mediated by phage while in Corynebacterium diphtheriae lysogenicity is an essential prerequisite for toxin production (Freeman \& Morse, 1952). 


\section{Transduction of virulence in $\mathrm{S}$. typhimurium}

Mouse virulence has not been transduced to the avirulent Salmonella typhimurium M206, although streptomycin resistance can be transferred. Similarly, the adenine-dependent mutant 1901 can be transformed to streptomycin resistance but not to prototrophy; thus the strain cannot be made virulent by transduction. Phage PLT22 propagated on strain 1901 can transduce adenineindependence to strains D2 and D 10, which indicates that the three strains are not allelic for adenine-dependence. It seems impossible to transfer any gene which would confer adenine-independence on strain 1901. Moreover, it has not been possible to obtain back mutations to prototrophy even when as many as $10^{11}$ organisms of strain 1901 were spread over minimal medium plates. Failure to transduce virulence to strain M206 and prototrophy to strain 1901, despite their susceptibility to transduction of streptomycin resistance, may indicate that these characters result either from mutation (or loss) of factors which cannot be transduced, e.g. a cytoplasmic particle or, more likely, from mutation of two or more factors, presumably unlinked, which cannot be transduced simultaneously by a single phage particle.

We wish to thank Brigadier J. S. K. Boyd, Dr T. W. Burrows, Dr M. Demerec, Dr O. Maaløe and Dr B. A. D. Stocker for strains of Salmonella typhimurium. We are greatly indebted to the late Dr A. Felix and Dr Joan Taylor for antigenic typing, Dr E. S. Anderson for phage typing and Dr C. M. P. Bradstreet for a gift of Salmonella typing sera. This work was done while one of us (G. F.) was holder of the Fleming Fellowship.

\section{REFERENCES}

Bacon, G. A., Burrows, T. W. \& Yates, M. (1951). The effects of biochemical mutation on the virulence of Bact. typhosum. The loss of virulence of certain mutants. Brit. J. exp. Path. 32, 85.

Davis, B. D. \& Mingioli, E. S. (1950). Mutants of Escherichia coli requiring methionine or Vitamin B12. J. Bact. 60, 17.

Felix, A. (1956). Phage typing of Salmonella typhimurium: its place in epidemiological and epizootiological investigations. J. gen. Microbiol. 14, 208.

Felix, A. \& Callow, B. R. (1943). Typing of paratyphoid-B bacilli by means of Vi bacteriophage. Brit. med. $J$. ii, 127.

Felix, A. \& Pitt, R. M. (1951). The pathogenic and immunogenic activities of S. typhi in relation to its antigenic constituents. J. Hyg., Camb. 49, 92.

Freeman, V. J. \& Morse, I. U. (1952). Further observations on the change to virulence of bacteriophage infected avirulent strains of Corynebacterium diphtheriae. J. Bact. 63, 407.

Gratia, A. (1936). Des relations numériques entre bactéries lysogènes et particules de bactériophage. Ann. Inst. Pasteur, 57, 652.

Griffith, F. (1928). The significance of pneumococcal types. J. Hyg., Camb. 27, 113.

MaAløe, O. (1948). I. Pathogenic-apathogenic transformation of Salmonella typhimurium. Acta path. microbiol. scand. 25, 414.

Miles, A. A. \& Misra, S. S. (1938). The estimation of the bactericidal power of the blood. J. Hyg., Camb. 38, 732.

Reed, L. J. \& Muench, H. (1938). A simple method of estimating fifty per cent end points. Amer. J. Hyg. 27, 493.

Zinder, N. D. \& Lederberg, J. (1952). Genetic exchange in Salmonella. J. Bact. 64,679 .

(Received 10 January 1956) 